\title{
New constraints for site-effect characterization from seismic noise analysis in southern Italy. San Fele case study
}

\author{
Margherita Corciulo ${ }^{1,2^{\star}}$, Paola Cusano ${ }^{3}$, Simona Petrosino $^{3}$ \\ ${ }^{1}$ Analisi e Monitoraggio del Rischio Ambientale (AMRA) S.c.ar.l., Napoli, Italy \\ ${ }^{2}$ Laboratoire de Géophysique Interne et Tectonophysique, Université J. Fourier, Grenoble, France \\ ${ }^{3}$ Istituto Nazionale di Geofisica e Vulcanologia, Osservatorio Vesuviano, Napoli, Italy
}

\section{Article history}

Received March 23, 2010; accepted September 7, 2010.

\section{Subject classification:}

Seismic risk, Seismic methods, Data processing, Waves and wave analysis, Instruments and techniques.

\section{ABSTRACT}

In the framework of ground-motion amplification analysis for southern Italy, the main target of this study is to provide new constraints on onedimensional, shallow-velocity profiles for a site in the San Fele area near the city of Potenza (southern Italy) where a permanent Irpinia Seismic Network (ISNet) seismic station is installed. Ambient noise vibrations were recorded during a seismic survey in San Fele, and the data acquired were used to define the shallow shear-wave velocity profiles and thicknesses of the shallow soil layers, through analysis of the dispersion characteristics of the surface waves. Single station and array techniques were used to obtain robust results, which show relatively flat curves of the $H / V$ spectral ratios and variations in shearwave velocities confined to the first $50 \mathrm{~m}$ in depth. On the basis of these results for the San Fele site, the present study aims to delineate a standard procedure that can be systematically applied to all of the other ISNet stations to improve site characterization. This will allow more accurate evaluation of peak ground-motion quantities (e.g. peak ground acceleration, peak ground velocity) at rock sites for use in shakemap analysis.

\section{Introduction}

In areas with high seismic-hazard levels, the correct evaluation of site amplification effects will allow the production of accurate ground-shaking maps that can reproduce the actual pattern of damage suffered by areas hit by an earthquake. The most common methods to analyze and quantify site effects are based on the shear-wave velocity (Vs) profile, the knowledge of which in the first $30 \mathrm{~m}$ (Vs30) has an important role in classification of the soil according to international schemes, such as for the National Earthquake Hazards Reduction Program [NEHRP 1997; Eurocode 8, 2003].

In recent years different techniques have been used to evaluate Vs profiles because knowledge of these allows evaluation of the site transfer function. Many studies have proposed the use of the geological characteristics to assign mean shear-wave velocity values to studied areas [Joyner and Boore 1981]. One of the main problems related to this technique is that detailed knowledge of the subsurface geology is required. To overcome this difficulty, several studies have proposed the use of the average of the shearwave velocities measured to a depth of $30 \mathrm{~m}$ (Vs30), in agreement with the typical depth reached by a drill rig in a single day [Joyner and Fumal 1985, Borcherdt et al. 1991].

In vertically heterogeneous media, surface waves are dispersive; i.e. their velocity depends on the frequency. This in turn controls their penetration depth [Aki and Richards 2002], and therefore a wider range of frequency allows a wider range of investigation depth. Different studies have been based on surface-wave dispersion to define shear-wave velocity profiles using active seismic sources (e.g. spectral analysis and multi-channel analysis of surface waves) [Nazarian et al. 1983, Park et al. 1999] and/or ambient noise vibrations. The main advantage of using ambient noise is in the wider range of frequencies available. Therefore, these methods represent useful, non-invasive and low-cost tools to determine the shear-wave velocities and thicknesses of soil layers, under the hypothesis that the noise wavefield is dominated by surface waves.

The spatial auto-correlation (SPAC) technique introduced by Aki [1957] is based on the assumption that seismic noise can be viewed as the sum of waves propagating in a horizontal plane in different directions with different powers, but with the same phase velocity for a given frequency [Aki 1965]. The phase velocity can be computed by estimating the space-correlation function for a fixed frequency without knowledge of the directionality of the waves. Then, varying the frequency, the phase velocity can be determined as a function of frequency. 
The original method of phase-velocity determination requires only a set of data acquired from a circular array with one seismometer placed at the center. In urban areas, and in a lot of other cases, this geometry is difficult to lay out. This led to some studies that improved on the original SPAC method, with the definition of the modified SPAC method (MSPAC) [Bettig et al. 2001]. Two further modifications were proposed by Cho et al. [2004, 2006] and Tada et al. [2006]: the centerless circular array (CCA) and the two-radius (TR) circular array methods, respectively.

In the present study, we follow the same approach of Di Giulio et al. [2006], which consists of application of both single-station [Nakamura 1989] and multi-channel techniques to seismic noise for complete site characterization of the test area of San Fele. Moreover, we applied the nonlinear methodology implemented by Wathelet [2005] and based on the neighborhood algorithm of Sambridge [1999], to invert the Rayleigh-wave dispersion curves and obtain the $S$-wave velocity profiles.

The test site was chosen in the framework of groundmotion amplification analysis for the Campania-Lucania region because it hosts one of the stations of the permanent Irpinia Seismic Network (ISNet) [Weber et al. 2007]. Our aim was to carefully evaluate the results obtained for the San Fele site to determine the applicability of the method to all of the other sites hosting ISNet stations. This will provide new constraints to compute site-specific coefficients for correct estimates of peak ground-motion quantities (e.g. peak ground acceleration, peak ground velocity, among others) at rock sites [Convertito et al. 2009]. The consequent accurate definition of ground-shaking maps will indeed be useful for the Civil Protection authorities to plan emergency actions in case of the occurrence of earthquakes.

\section{Geological framework}

The Campania-Lucania region (southern Apennines) has experienced numerous disastrous earthquakes that have made it one of the highest seismic-risk areas in Italy [Cinti et al. 2004]. This area therefore represents a natural laboratory to implement and test methodologies for the evaluation of site amplification and for investigation of the characteristics of seismic earthquakes.

A Quaternary-Volcanic-Tertiary-Mesozoic (QVTM) site-condition map for the Campania-Lucania region was proposed recently [Cantore 2008]. This map is based on the geological units that outcrop in this area and on the Vs profiles available from the database of the National Strong Motion Network (RAN). The accuracy of this map depends on the availability of Vs profiles, and as stated by the authors, the accuracy increases as more Vs profiles become available.

The structural geology of the San Fele area is characterized by an antiformal that involves different layers of the Lagonegro Unit superimposed tectonically. This Unit is characterized by complex stratification of siliceous claystones, cherty limestones, and dolomites, down to a depth of about 5,000 m, as inferred by the San Fele well that was drilled in the area [Improta et al. 2003, Patacca 2007].

\section{Acquisition layout}

The data analyzed in this study were collected by a group of researchers of the Analisi e Monitoraggio del Rischio Ambientale (AMRA) S.c. a r.l. society of Naples and of the Istituto Nazionale di Geofisica e Vulcanologia, Osservatorio Vesuviano (INGV department in Naples), who installed three temporary seismic arrays to measure ambient noise in the area of San Fele, near the city of Potenza (southern Italy) (Figure 1). The instrumentation comprised four portable

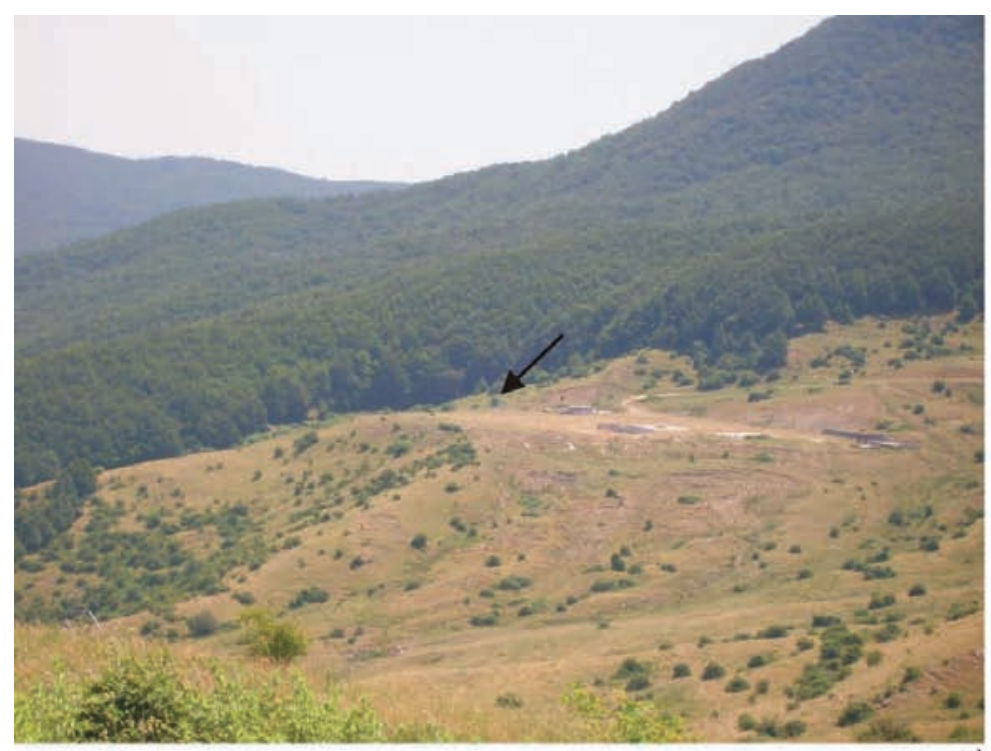

a)

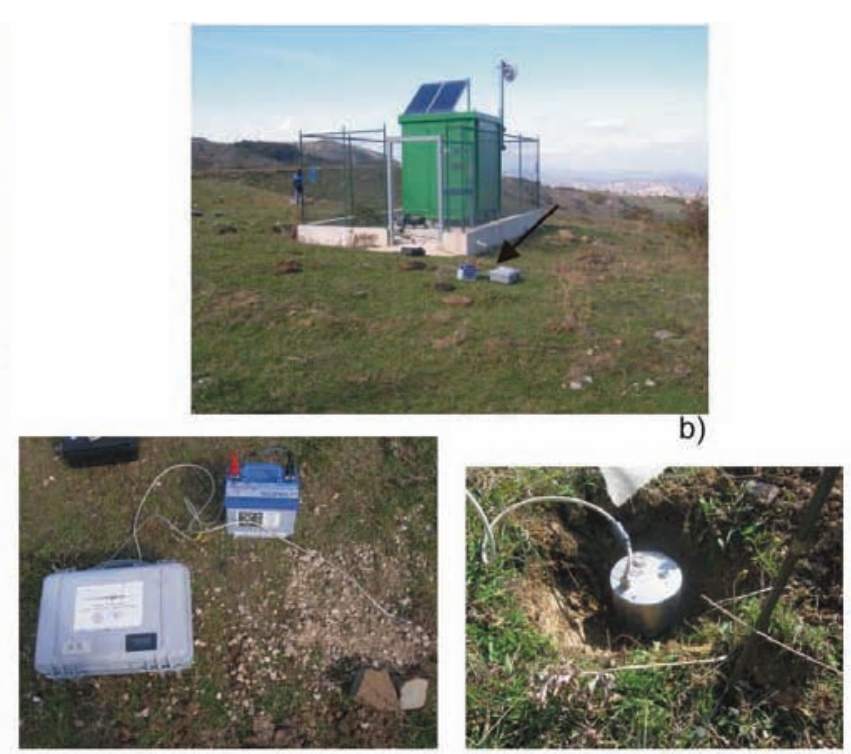

c)

Figure 1. (a) Survey area. Arrow, location of the SFL3 shelter. (b) The SFL3 ISNet station shelter. Arrow, position of the temporary seismic station (A2) used during the noise acquisition survey. (c) The complete portable station: Lennartz MarsLite, battery and buried seismometer. (d) The LE3D 1-Hz seismometer in the hole. 


\begin{tabular}{cccc}
\hline Array name & Starting time & Ending time & $\boldsymbol{k}_{\min }-\boldsymbol{k}_{\max }$ \\
\hline \multirow{2}{*}{ A } & $2008-10-28$ & $2008-10-28$ & $11: 55: 24$ \\
& $10: 59: 08$ & $2008-10-28$ & $0.234-0.5310$ \\
B & $2008-10-28$ & $10.48: 24$ & $0.064-0.1450$ \\
& $09: 11: 12$ & $2008-10-27$ & $16: 01: 08$ \\
\hline
\end{tabular}

Table 1. Timetable and resolution limits $\left(k_{\min }\right.$ and $\left.k_{\max }\right)$ for each array. Resolution limits are the minimum and the maximum resolvable wavenumbers.

digital Lennartz MarsLite stations equipped with $1-\mathrm{Hz}$ Le3Dlite seismometers, which were located close to the SFL3 ISNet permanent station at $15.5782{ }^{\circ} \mathrm{E}$ and $40.7889^{\circ} \mathrm{N}$. The sampling rate and gain were set to $125 \mathrm{~Hz}$ and $8 \mu \mathrm{V} /$ count, respectively. All of the seismometers were buried in $20-\mathrm{cm}-$ deep holes and oriented to geographic North.

The map in Figure 2 shows the location of the area of acquisition (red circle, upper-right corner panel). The gray triangle corresponds to the location of the SFL3 permanent ISNet station. Figure 2 clearly shows the triangular geometry of the arrays used during the experiment. Three stations were deployed in three concentric triangular configurations, with rays of about $10 \mathrm{~m}, 40 \mathrm{~m}$ and $80 \mathrm{~m}$; the remaining station was fixed at the center during the entire experiment. This particular configuration was chosen to obtain the widest azimuthal coverage; therefore, the stations were deployed with a distance of $120^{\circ}$ each from the others. The data were collected in three times, with the timetable shown in Table 1. Figure 3 shows an example of the data that was acquired for the outer array, with the seismograms acquired for the three components shown on the left, and the relative spectra plotted on the right. The experiment was carried out from 27 to 28 October, 2008.

\section{Data analysis}

The ambient vibration data recorded at San Fele were analyzed using both single-station and array techniques implemented in the GEOPSY software (Geophysical Signal Database for Noise Array Processing), which is distributed in the framework of the Site Effects Assessment using Ambient Excitations (SESAME) project (2001-2004) [SESAME WP05, 2002]. The surface-wave-dispersion curve obtained has been inverted, to define a velocity profile for the area studied.

\section{Single station analysis ( $\mathrm{H} / \mathrm{V}$ ratio)}

The data were analyzed using the method of Nakamura $[1989,2000]$, which was applied to the recordings from each single station to compute the spectral ratio between the horizontal and the vertical components (H/V ratio). This method allows the identification of the fundamental resonance frequency for each site when the impedance contrast between the surface and the deep material is high [Bard 1998].

The importance of $\mathrm{H} / \mathrm{V}$ peak estimation in the framework of the $S$-wave velocity profile definition has been analyzed in different studies [e.g. Bonnefoy-Claudet 2004] that have shown that the resonance frequency for a site is close to the $\mathrm{H} / \mathrm{V}$ peak and depends on the layer thickness and the $S$-wave velocity. This means that the $\mathrm{H} / \mathrm{V}$ peak gives additional constraint to the $S$-wave velocity profile estimation.

The results obtained through applying the H/V method to each station of the array are shown in Figure 4. These results were obtained by using all of the data recorded. The horizontal component considered in the computation was the squared average of the East-West and North-South components. To study the stability and the reliability of the

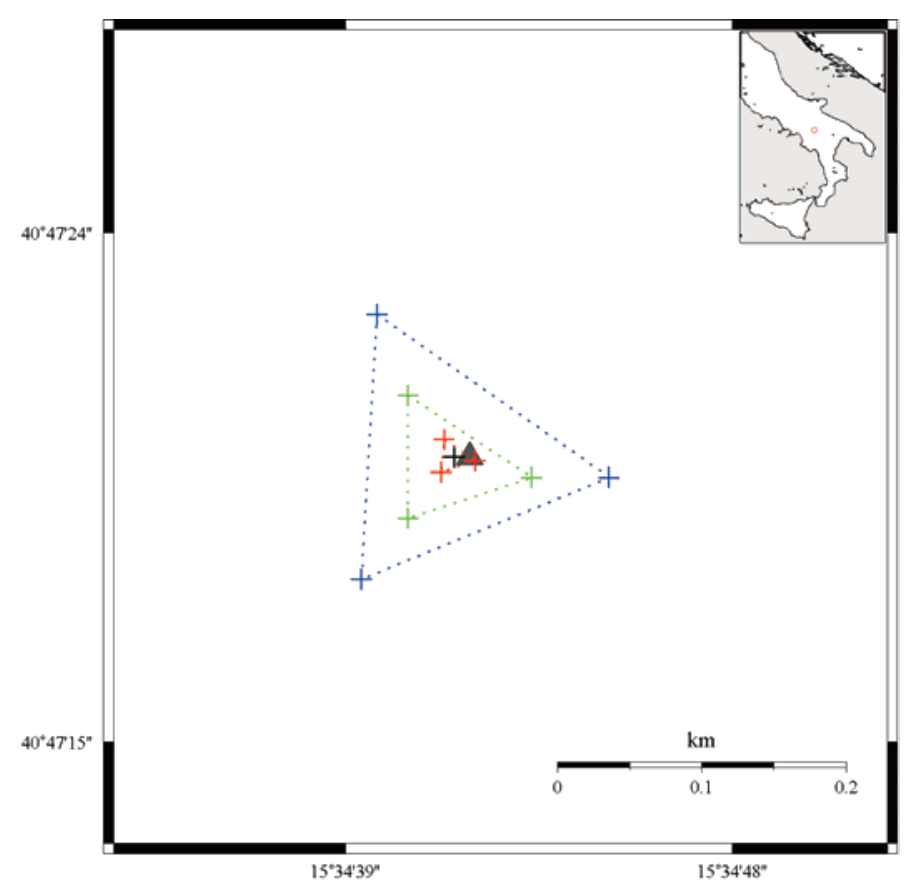

Figure 2. Acquisition geometry. Crosses, locations of the temporary stations. Gray triangle, the SFL3 station location. The different colours correspond to the different arrays. Dotted lines, the three triangular configurations used. Red, inner array; green, middle array; blue, outer array. 

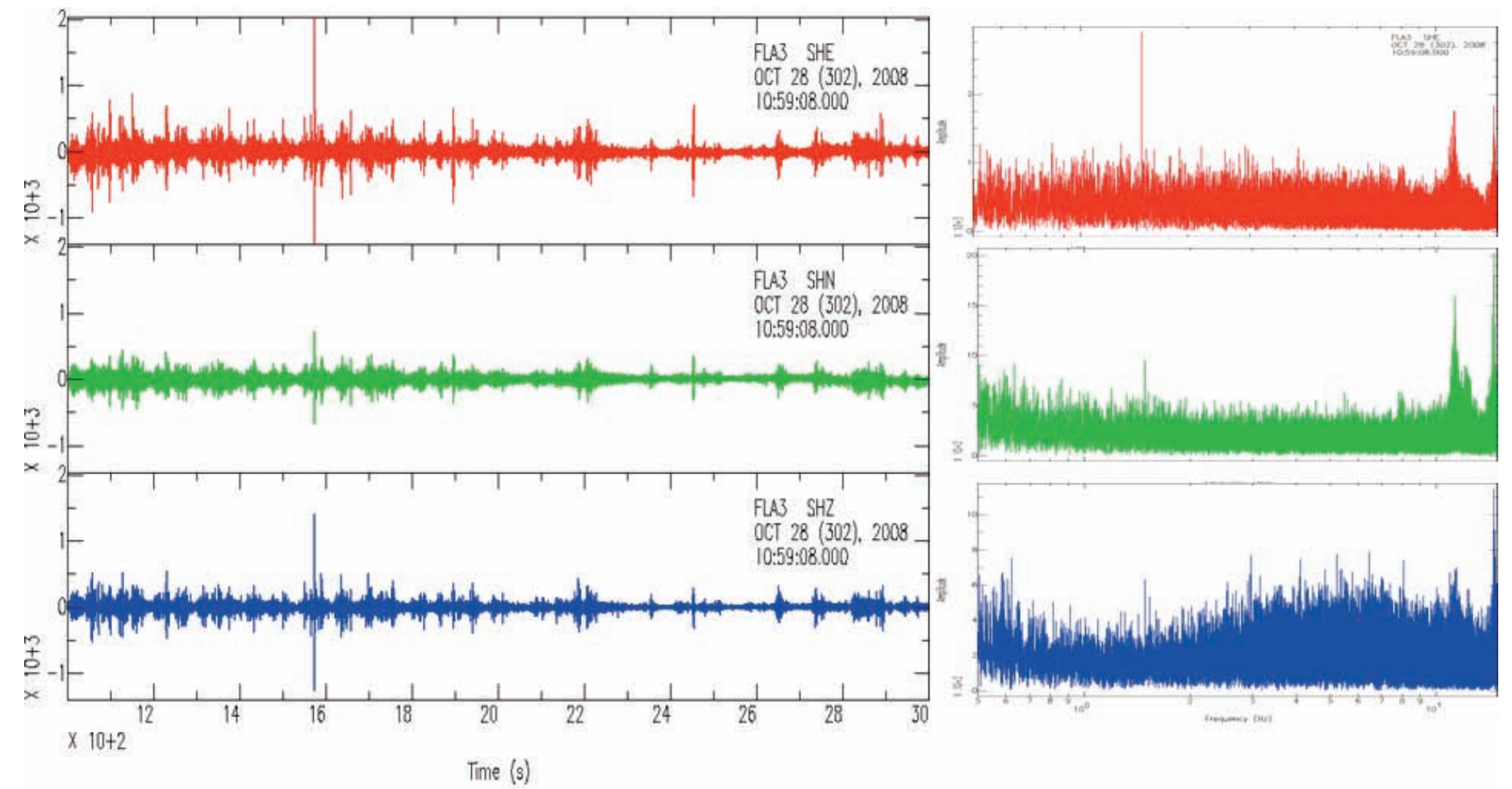

Figure 3. Example of the data acquired. Left: seismic noise records acquired for the outer array for the EW (top), NS (middle) and vertical (bottom) components. Right: relative computed spectra for the noise acquired.
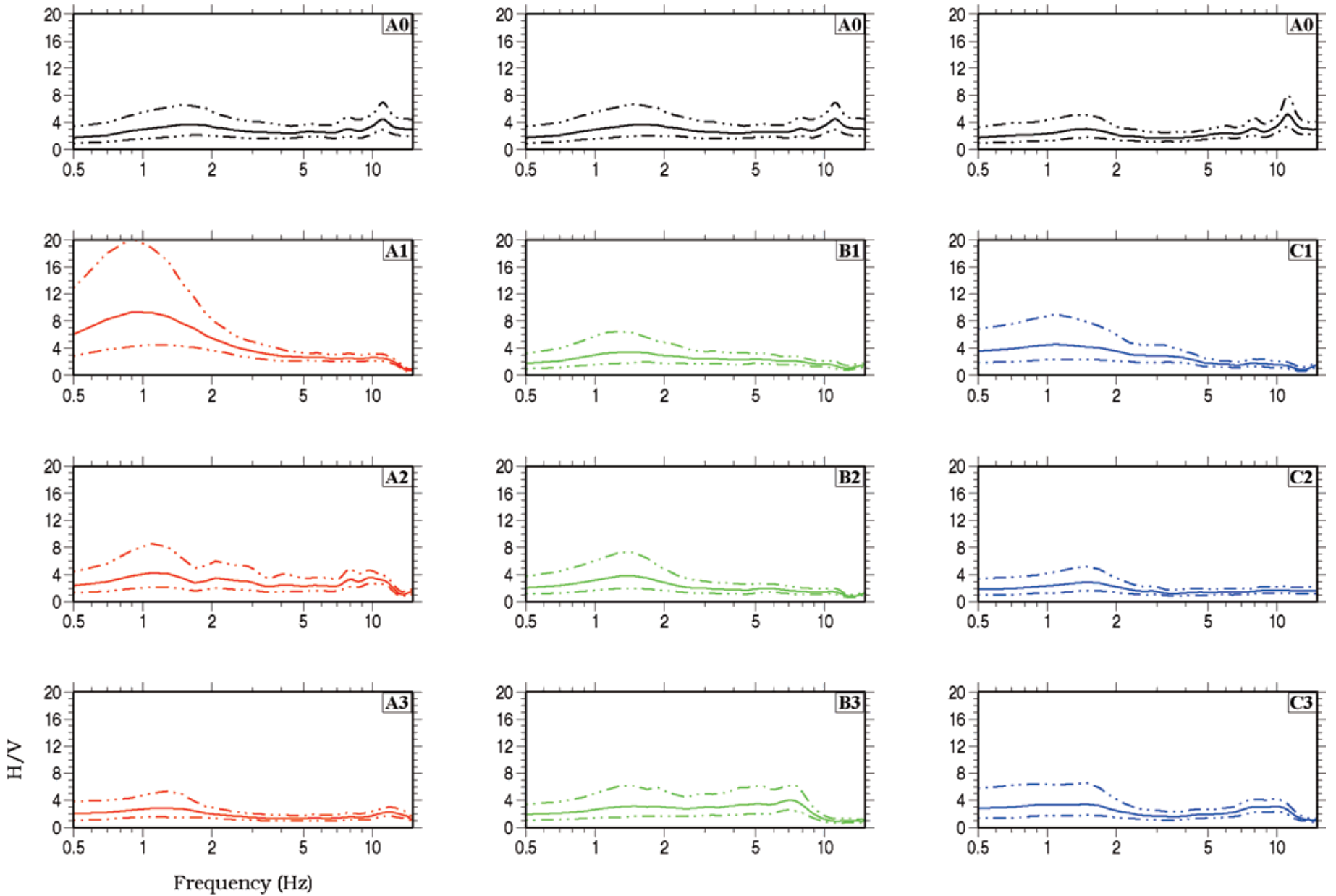

Figure 4. Mean H/V (continuous lines) and standard deviation (dashed lines) functions computed for each array. From left: the inner, middle and outer arrays. 

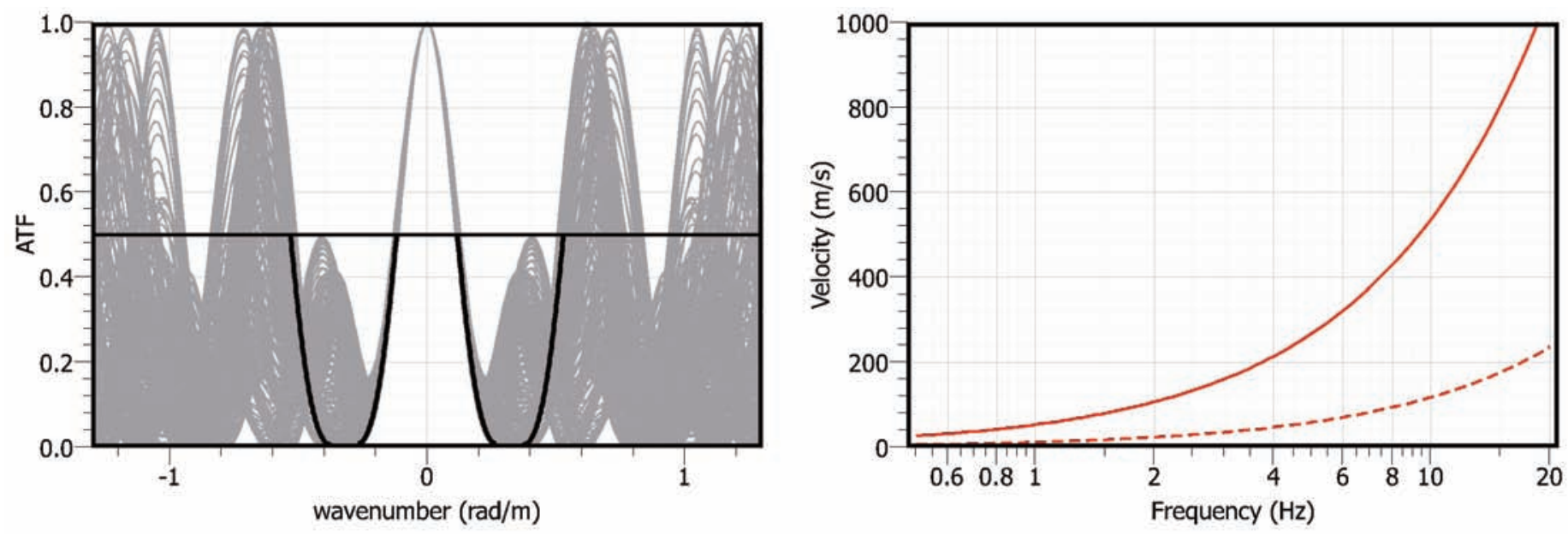

Figure 5. Array transfer function (ATF) for array A. Left: Azimuthal projection of the ATF amplitude as a function of the wavenumber $k$. Right: the Vs versus frequency curves corresponding to the minimum (continuous line) and maximum (dashed line) resolvable wavelengths ( 0.234 and 0.5310 , respectively).

results obtained, several tests have been carried out, through changing the parameters used, as well as working on the raw and filtered signals. This included, time windows ranging from $5 \mathrm{~s}$ to $50 \mathrm{~s}$, smoothing values ranging from 10 to 40 , and Butterworth band-pass filtering between $1 \mathrm{~Hz}$ and $15 \mathrm{~Hz}$. All of the results obtained showed the same peaks, with little change in the amplitudes and the widths.

Figure 4 shows the best mean H/V functions obtained for each station using a long-term average/short-term average (LTA/STA) antitrigger algorithm on the raw signals, with the LTA fixed a $30 \mathrm{~s}$ and the STA fixed at $1 \mathrm{~s}$, a time window of 5 s, and the Konno and Ohmachi [1998] smoothing procedure with a smoothing value fixed at 40 . A rapid analysis of Figure 4 allows it to be stated that except for the A0 station, there is no evidence of a resonant frequency for the San Fele site. Analyzing the data thoroughly for the A0 station, i.e. for both of the two days of acquisition, a peak appears at a frequency of $11 \mathrm{~Hz}$. As it has been indicated from several studies [Fabbrocino, personal communication; Cantore 2008], this peak is due to the presence of the shelter, the structure hosting the permanent station (Figure 1, black arrow). The other peaks in the plots are also of no significance, as they do not respect the criteria for a «clear peak» proposed in the guidelines published in the framework of the SESAME project [SESAME WP12, 2004]. These peaks are very wide (Figure 4, A1, B1, B2, C1) or their sharp decrease is evident only on one side (B3). These features mean that these peaks are not reliable for the resonance analysis.

\section{Array analysis}

The array data analysis was performed using the modified MSPAC method to define the dispersion curve for each array [Bettig et al. 2001]. The dispersion curves retrieved were inverted to obtain the $S$-velocity profile for the San Fele site. For each array, the array transfer function (ATF) was computed, as defined as the array response for a vertically incident impulsive signal. The ATF is commonly used to determine the resolution of array configurations and to determine the dependence of the aliasing on the azimuth, in the wavenumber domain [Woods and Lintz 1973].

We computed the ATF for a frequency band defined from the spectral analysis (Figure 3) and ranging from $0.5 \mathrm{~Hz}$ to $20 \mathrm{~Hz}$. As an example, Figure 5 shows the results obtained for the smallest array (array A), with the results for vertical sections of the ATF amplitude versus wavenumber on the left. The right side of Figure 5 shows the resolution limits retrieved. In particular, these curves, and those obtained for the others two arrays, were used in the MSPAC analysis to validate the retrieved dispersion curves. The resolution limits are defined by the $k_{\min }$ and $k_{\max }$ values that are the minimum and maximum wavenumbers, respectively, that can be solved with the configuration used. The lowest wavenumber $\left(k_{\min }\right)$ is defined as the value of the main peak that reaches the ATF magnitude of 0.5 (Figure 5, black horizontal line). The maximum wavenumber $\left(k_{\max }\right)$ is defined, instead, as the wavenumber of the secondary peak (the closest to the principal one) that exceeds the ATF magnitude of 0.5 [Di Giulio et al. 2006]. Table 1 shows the values retrieved for each of the array configurations.

The MSPAC method computes the averages of the spatial auto-correlation ratio on the rings, including all of the possible pairs of stations defined, starting from the location of each of the stations of the array used. The concept of the ring has been introduced to provide the imperfectly shaped array (as required in the SPAC method), both in terms of rays and angles $(r, \varphi)$. Using the concept of the rings, only the relative locations of the station pairs must be taken into account in the computation of the correlation values. In other words, the MSPAC analysis computes the averages of the spatial auto-correlation ratios in the plane $(r, \varphi)$ on the rings with rays $r_{1} ; r_{2}$, where $r_{1}<r<r_{2}$.

In its general formulation, the SPAC method allows computation of the spatial auto-correlation ratio for each frequency, using the following equation: 


$$
\overline{\rho_{z}}(r, \omega)=J_{0}\left[\frac{\omega r}{c_{R}(\omega)}\right]
$$

where $\overline{\rho_{z}}(r, \omega)$ is the spatial auto-correlation ratio computed using the vertical component of the noise; $J_{0}$ is the Bessel function of zero order; $\omega$ is the angular frequency, and $r$ is the radius. Finally $c_{R}(\omega)$ is the phase velocity of the dispersive Rayleigh waves. Knowing $\overline{\rho_{z}}(r, \omega)$ at several frequencies, the phase velocity profile can be estimated.

However, Equation (1) holds true if the data have been acquired using a perfect circular array geometry. In the case of irregular arrays, the average of the spatial auto-correlation ratio must be computed, so the MSPAC formulation must be used.

Using the rings concept, a given array can be divided into several semicircular sub-arrays $k$, defined by a pair of stations $(i, j)$ having a spacing $r_{i j}$ such that $r_{k 1}<r_{i j}<r_{k 2}$. For each sub-array, the average of the spatial auto-correlation ratio can be computed using:

$$
\overline{\rho_{k}}(\omega)=\frac{1}{\pi} \sum_{r_{k 1}<r_{i j}<r_{k 2}} \rho\left(r_{i j}, \varphi_{i j}, \omega\right) \Delta \varphi_{i j}
$$

where $\varphi_{i j}$ is the azimuth between the stations $(i, j)$. Thus, knowing the average of the spatial auto-correlation ratio, the $c_{R}$ value of Equation (1) can be computed for a given frequency. In other words, knowing $\overline{\rho_{k}}(\omega)_{i j}$, the dispersion curves can be estimated.

\section{Dispersion Curves}

The vertical components of the data acquired were used to compute the dispersion curves for each array. The data were processed using a classical procedure to synchronize all of the signals and to remove the mean and the trend using SAC algorithms [Goldstein et al. 2003]. Table 1 gives the timetable for each array configuration. To compute the theoretical depth of investigation for each array, we used the Tokimatsu [1997] criteria, known as the $\lambda / 3$ criteria:

$$
d_{\max }=\frac{\lambda_{\max }}{3}=\frac{2 \pi}{3 k_{\min }}
$$

where $k_{\text {min }}$ is the minimum wavenumber retrieved computing the ATF function. A theoretical depth of about $90 \mathrm{~m}$ was computed for the largest aperture array (array C).

The use of several aperture arrays allows to solve a wider range of frequencies. Therefore, by combining together the results for the three arrays, we were able to solve a bandwidth from $1 \mathrm{~Hz}$ to $20 \mathrm{~Hz}$. Figure 6 shows the mean dispersion curves retrieved, with the colors used to identify the arrays used. In Figure 6, we represent together the mean dispersion curves retrieved (in bold) and the resolution curves retrieved with the ATF analysis for all of the three arrays. For each of the dispersion curves, we also plotted the computed error bars that give information on the reliability of the curve. The red curve

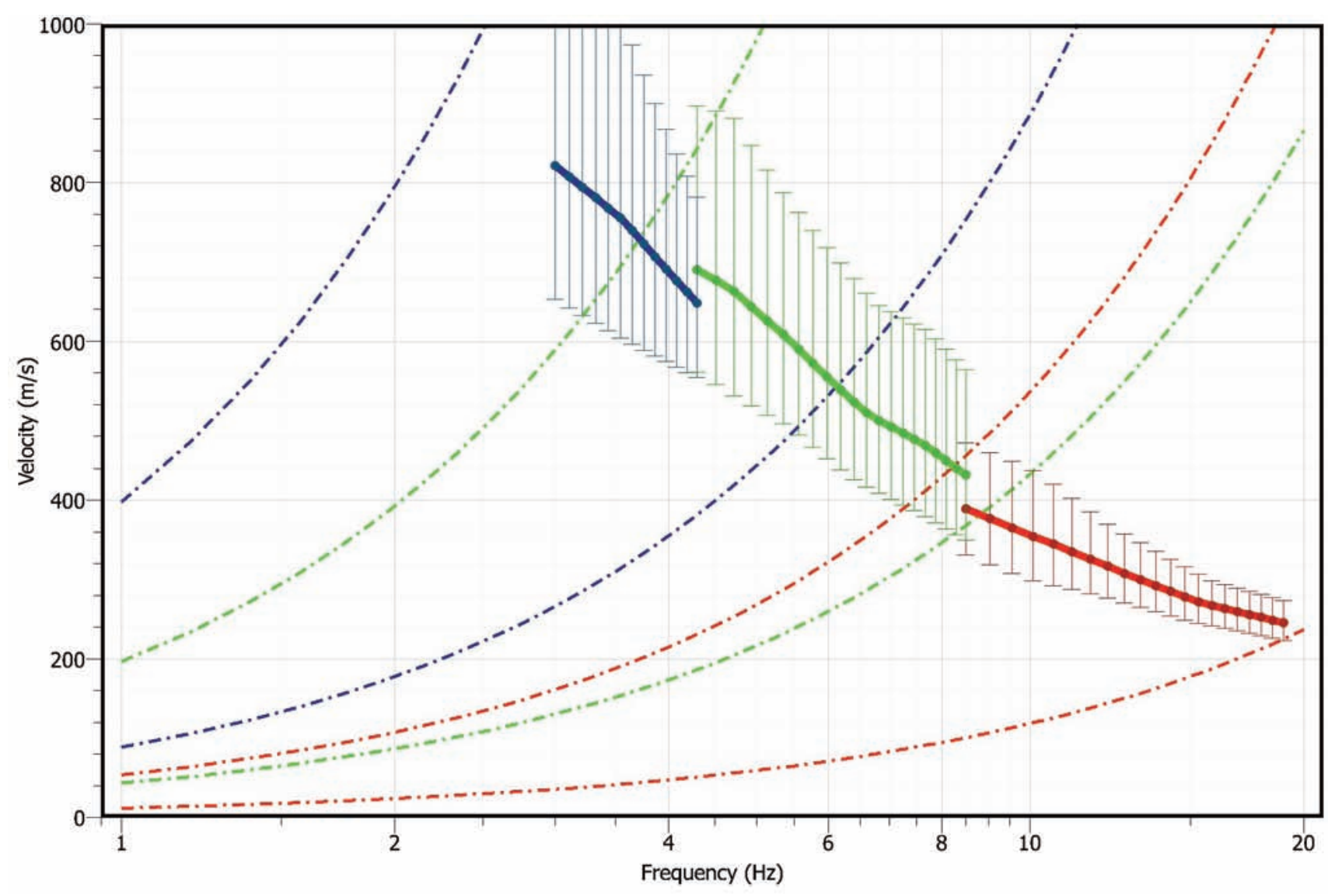

Figure 6. Dispersion curves (continous lines) obtained from the correlation coefficients for the three arrays. Vertical bars, errors computed for each dispersion curve. Dashed lines, minimum and maximum resolvable wavelengths retrieved for each array. Blue, outer array; green, middle array; red, inner array. 


\begin{tabular}{|c|c|c|c|c|c|c|c|c|}
\hline \multicolumn{7}{|c|}{ Sedimentary layer } & \multicolumn{2}{|c|}{ Bedrock } \\
\hline \multirow{2}{*}{$\begin{array}{c}\text { Number } \\
\text { of sub-layer }\end{array}$} & \multicolumn{2}{|c|}{ Thickness $(m)$} & \multicolumn{2}{|c|}{$\operatorname{Top}(\mathrm{m} / \mathrm{s})$} & \multicolumn{2}{|c|}{$\operatorname{Bottom}(\mathrm{m} / \mathrm{s})$} & \multirow[b]{2}{*}{ Vmin } & \multirow[b]{2}{*}{ Vmax } \\
\hline & Min & Max & Vmin & $V \max$ & Vmin & $V \max$ & & \\
\hline & 1 & 100 & 150 & 3500 & & & 1000 & 4500 \\
\hline & 1 & 1000 & 50 & 2500 & & & 1000 & 4500 \\
\hline 2 & 1 & 500 & 50 & 500 & 150 & 1000 & 1000 & \\
\hline 4 & 1 & 100 & 50 & 350 & 300 & 800 & 1000 & 3000 \\
\hline 10 & 1 & 100 & 50 & 1000 & 500 & 2000 & 500 & 2000 \\
\hline 1000 & 1 & 90 & 50 & 500 & 150 & 1500 & 50 & 3500 \\
\hline
\end{tabular}

Table 2. Velocity and thickness parameters used in the inversion procedure.

in Figure 6 appears to be better constrained, which is due to the high-density solution retrieved in the frequency-velocity grid obtained after seeking all of the possible solutions for the data [Wathelet et al. 2005]. Starting from these three curves, we computed a single mean dispersion curve that was used to obtain the $S$-wave velocity profile.

\section{Inversion}

The mean dispersion curve computed for the data acquired was inverted to obtain the $S$-wave velocity profile using the implementation of the neighborhood algorithm [Sambridge 1999] performed by Wathelet et al. [2004]. This implementation allows the generation of random velocity models, which are then used to compute the theoretical dispersion curves. To find the best velocity model, the theoretical dispersion curves are compared to the experimental ones, and the misfit value is computed. The solution of the inversion, i.e. the final velocity model, is that which has the lower misfit value.

As in all classical inversion problems, we had to define the data to invert and the parameters to retrieve. In our case, the data were represented by the mean dispersion curve computed for the vertical component of the ambient noise. The parameters were, instead, the $S$-wave velocity and the thickness of the soil layer. To explore all of the parameter space of the velocity models and to choose the best one, we used a trial-and-error procedure. As the geological model known for the area, which comes from well data, is available only for the $P$-wave, we cannot use this as the starting model in our procedure. Nonetheless, we can use information about the structure and density values.

Using this little information, we assumed a velocity model as a two-layered structure: a sedimentary layer over a bedrock. By studying the best-fit model retrieved, as the inversion proceeded, we were able to modify our parameters ( $S$-wave velocity and thickness range). Starting from this simple two-layered model, we moved towards a more complicated sedimentary layer, increasing the number of its sub-layers (Table 2). Finally, the best model retrieved had 1,000 sub-layers in the sedimentary layer over a bedrock. This high number of sub-layers allows us to assume a gradient feature for the sedimentary layer, in agreement with the $P$-wave velocity profile known for the area. To test the robustness of the final model retrieved, and to randomly explore all of the parameter space, we ran 3 to 4 inversion processes for each set of parameters (Table 2) using different seeding (i.e. starting model) and exploring about 7,000 models for each run.

Figure 7 shows the one-dimensional $S$-wave velocity model obtained, and the corresponding dispersion curves. The Vs model shows a velocity gradient for the sedimentary layer ranging from $200 \mathrm{~m} / \mathrm{s}$ to $800 \mathrm{~m} / \mathrm{s}$ down to about $50 \mathrm{~m}$ in depth. Each model explored in Figure 7 is plotted using a color that corresponds to the computed misfit value. All of the models approach the best-fit model (Figure 7, red). This agreement is evident down to $40 \mathrm{~m}$, while instead a broader convergence appears for the bedrock velocity. The variability in the range of a $40-50 \mathrm{~m}$ depth does not have great relevance. The misfit values computed for the profiles plotted in pink in Figure 7 are the highest that were retrieved in the entire inversion process, and this means that these models are those that are badly constrained.

The fundamental Rayleigh-wave dispersion curves computed for all of the models retrieved are also plotted in Figure 7 , and they are compared with the experimental model (Figure 7, black solid line). Figure 7 also shows the convergence of the velocity profiles. All of the theoretical dispersion curves fit the uncertainty of the mean dispersion curve very well, as indicated by the error bars, which confirms the robustness of the result obtained. The amplitude of the error bars is larger at low frequency, which corresponds to greater depth of exploration. This can be related to the increasing uncertainty of the phase-velocity estimate at lower frequency, and to the decrease in the sensitivity with depth.

\section{Conclusions}

In this study, we have shown the results of the seismic noise analysis performed on data acquired at the San Fele site 

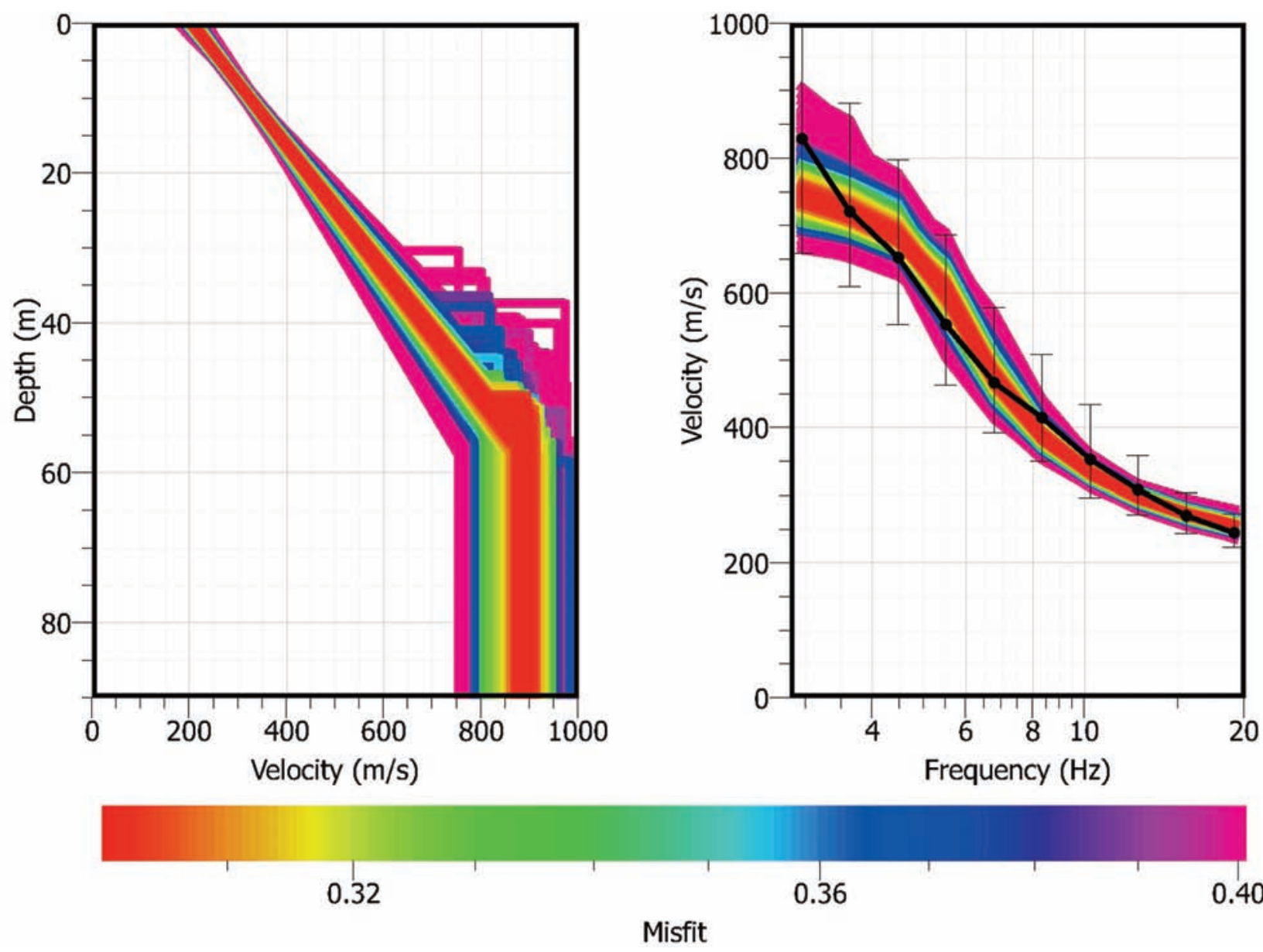

Figure 7. $S$-wave velocity profiles (left) and theoretical dispersion curves (right).

(southern Apennines). The aim of this study was to investigate the feasibility of the MSPAC methodology to obtain $S$-wave velocity profiles from ambient noise vibration data also in very complex areas, such as the southern Apennines. We used both single-station and array data analysis, obtaining results that are in agreement.

The single station analysis, which were performed using the $\mathrm{H} / \mathrm{V}$ methodology, show that no resonance frequency characterizes the San Fele site. This might mean that there is no high-velocity contrast between the soil-layer and the bedrock at the site. This result is confirmed by that obtained using the MSPAC methodology. Indeed, Figure 7 shows that a gradient $S$-wave velocity profile is obtained down to about $50 \mathrm{~m}$, and that there is no abrupt change in the velocity of the underlying layer.

Furthermore, the procedure used has allowed simulation of quite a complex model in the sedimentary layer, i.e. a velocity gradient, using a simple two-layered model. We assume that the gradient velocity profile retrieved is probably due to the presence of a single tectonic unit, for which the velocity variation gives information as to the different degrees of alteration and/or different sizes of the grain. This is supported by the data from the San Fele well, which was drilled down to a depth of about 5,000 m, and encountered a pile of imbricate deposits that are referable to the Lagonegro unit [Patacca 2007, Improta et al. 2003]. The data available for this well show that down to about $40 \mathrm{~m}$ in depth the lithology is referred to as marly shale deposits that overlap shale and siliceous shale deposits. These data appear to explain the broader convergence of the $S$-wave velocity profile that is obtained at the depth of 40-50 $\mathrm{m}$ (Figure 7). With reference to the NEHRP classification, the area of San Fele can be classified in the C class, as dense soil and unconsolidated rocks due to the high number of fractures.

The present study shows once again that the combined use of $\mathrm{H} / \mathrm{V}$ and MSPAC methodologies provides robustness for the results obtained. Moreover, the use of ambientnoise vibration data is a very useful, non-invasive and low-cost method to obtain shear-wave velocity profiles and thicknesses of soil-layers.

Finally, the Vs profile is one of the most important pieces of information for the assessing of site effects in earthquake engineering. For this reason, we believe that the methodology applied to the San Fele site is very useful in the seismic-risk assessment for the southern Apennines.

Acknowledgements. This study was supported financially by AMRA S.c. ar.l. (www.amra.unina.it) in the framework of the SAFER-SERISK project (Sixth Framework Programme for Sustainable Development, Global Change and Ecosystem Priority, 6.3.IV.2.1: Reduction of seismic risks for specific targeted research or innovation projects; contract no. 036935). Dr. Danilo Galluzzo is greatly acknowledged for his contributions to the data acquisition. 


\section{References}

Aki, K. (1957). Space and time spectra of stationary stochastic waves, with special reference to microtremors, B. Earthq. Res I. Tokyo, 35, 415-456.

Aki, K. (1965). A note on the use of microseisms in determining the shallow structures of the Earth's crust, Geophysics, 30 (4), 665-666.

Aki, K., and P.G. Richards (2002). Quantitative Seismology, 2nd Ed., University Science Books, Sausalito, California, $704 \mathrm{pp}$.

Bard, P.Y. (1998). Microtremor measurements: A tool for site effect estimation?, In: K. Irikura, K. Kudo, K. Okada and T. Sasatami (eds.), The Effects of Surface Geology on Seismic Motion: Recent Advances Progress and New Horizon on EGS study, Proceedings of the 2nd Symposium (Yokohama, Japan, 1-3 December 1998), Rotterdam, 1251-1279.

Bettig, B., P. Bard, F. Scherbaum, J. Riepl, F. Cotton, C. Cornou and D. Hatzfeld (2001). Analysis of dense array noise measurements using the modified spatial auto-correlation method (SPAC): application to the Grenoble area, B. Geofis. Teor. Appl., 42 (3-4), 281-304.

Bonnefoy-Claudet, S. (2004). Nature du bruit de fond sismique: implication pour les études des effets de site, Ph.D. thesis, Université Joseph Fourier, LGIT, Grenoble, France.

Borcherdt, R.D., C.M. Wentworth, A. Janssen, T. Fumal and J. Gibbs (1991). Methodology for predictive GIS mapping of special study zones for strong ground motion in the San Francisco bay region, CA, In: Proceedings of the Fourth International Conference on Seismic Zonation, (Stanford, California, August 25-29, 1991), Earthquake Engineering Research Institute, III, 545-552.

Cantore, L. (2008). Determination of site amplification in the Campania-Lucania region (southern Italy) by comparison of different site-response estimation techniques, Ph.D. thesis, Università Federico II di Napoli; http: / / www.fedoa. unina.it/3407/.

Cho, I., T. Tada and Y. Shinozaki (2004). A new method to determine the phase velocities of Rayleigh waves from microseisms, Geophysics, 69, 1535-1551.

Cho, I., T. Tada and Y. Shinozaki (2006). Centerless circular array method: inferring phase velocity of Rayleigh waves in broad wavelength ranges using microtremor records, J. Geophys. Res., 111, B09315; doi: 10.1029/2005JB004235.

Cinti, F.R., L. Faenza, W. Marzocchi and P. Montone (2004). Probability map of the next $\geq 5.5$ earthquakes in Italy, Geochem. Geophy. Geosy., 5, 11, Q11003; doi: 10.1029/ $2004 \mathrm{GC} 000724$.

Convertito, V., R. De Matteis, L. Cantore, A. Zollo and G. Iannaccone (2009). Rapid estimation of ground-shaking maps for seismic emergency management in the Campania region of southern Italy, Nat. Hazards, 52 (1), 97115; doi: 10.1007/s11069-009-9359-2.

Di Giulio, G., C. Cornou, M. Ohrnberger, M. Wathelet and
A. Rovelli (2006). Deriving wavefield characteristics and shear-velocity profiles from two-dimensional smallaperture arrays analysis of ambient vibrations in a smallsize alluvial basin, Colfiorito, Italy, B. Seismol. Soc. Am., 96, 1915-1933.

Eurocode 8 (2003). Design of Structures for Earthquake Resistance, Part I: General Rules, Seismic Actions and Rules for Buildings, European Committee for Standardization/ Comité Européen de Normalisation, Doc CEN/TC250/ SC8/N335, Draft No. 6.

Goldstein, P., D. Dodge, M. Firpo and L. Minner (2003). SAC2000: Signal processing and analysis tools for seismologists and engineers, International Geophysics, 81 (2), 1613-1614.

Improta, L., M. Bonagura, P. Capuano and G. Iannaccone (2003). An integrated geophysical investigation of the upper crust in the epicentral area of the 1980, Ms $=6.9$, Irpinia earthquake (southern Italy), Tectonophysics, 361, 139-169.

Joyner, W.B., and D.M. Boore (1981). Peak horizontal accelerations and velocity from strong-motion records including records from the 1979 Imperial Valley, California earthquake, B. Seismol. Soc. Am., 71, 2011-2038.

Joyner, W.B., and T.E. Fumal (1985). Predictive Mapping of Earthquake Ground Motion, In: Evaluating Earthquake Hazards in the Los Angeles Region, USGS Professional Paper No. 1360, 203-220.

Konno, K., and T. Omachi (1998). Ground motion characteristics estimated from spectral ratio between horizontal and vertical components of microtemors, B. Seismol. Soc. Am., 88 (1), 228-241.

Nakamura, Y. (1989). A method for dynamic characteristics estimation of subsurface using microtremor on the ground surface, Railway Technical Research Institute, Quarterly Reports, 30 (1), 25-33.

Nakamura, Y. (2000). Clear identification of fundamental idea of Nakamura's technique and its applications, In: Proceedings of the 12th World Conference of Earthquake Engineering, Auckland, New Zealand.

Nazarian, S., K.H. Stokoe and W.R. Hudson (1983). Use of spectral analysis of surface waves method for determination of moduli and thicknesses of pavement systems, Transport. Res. Rec., 930, 38-45.

NEHRP (1997). NEHRP Recommended Provisions for Seismic Regulation for New Buildings and Other Structures, Part 1: Prevision, 1997 Edition, Prepared by the Building Seismic Safety Council (National Institute of Building Sciences) for the Federal Emergency Management Agency, Washington, D.C.

Park, C.B., R.D. Miller and J. Xia (1999). Multi-channel analysis of surface waves, Geophysics, 64, 800-808.

Patacca, E. (2007). Stratigraphic constraints on the CROP-04 seismic line interpretation: San Fele 1, Monte Foi 1 and 
San Gregorio Magno 1 wells (Southern Apennines, Italy), In: A. Mazzotti, E. Patacca and P. Scandone (eds.), Results of the CROP Project, Sub-project CROP-04 Southern Apennines (Italy), B. Soc. Geol. Ital., 7, 185-239.

Sambridge, M. (1999). Geophysical inversion with a neighborhood algorithm I. Searching a parameter space, J. Geophys. Res., 103, 4839-4878.

SESAME WP05 (2002). Site effects assessment using ambient excitations. Optimum deployment strategy for array measurements. European Commission - Research General Directorate Project No. EVG1-CT-2000-00026 SESAME. SESAME European research project WP05 Deliverable D07.05.

SESAME WP12 (2004). Site-effects assessment using ambient excitations. Guideline for implementation of the $\mathrm{H} / \mathrm{V}$ spectral ratio technique on ambient vibrations: measurements, processing and interpretation, European Commission - Research General Directorate Project No. EVG1-CT-2000-00026 SESAME. SESAME European research project WP12 - Deliverable D23.12.

Tada, T., I. Cho and Y. Shinozaki (2006). A two-radius circular array method: inferring phase velocities of Love waves using microtremor records, Geophys. Res. Lett., 33, L10303; doi: 10.1029/2006GL025722.

Tokimatsu, K. (1997). Geothermal site characterization using surface waves, In: K. Ishihara (ed.), Earthquake Geotechnical Engineering, Rotterdam, 1333-1368.

Wathelet, M., D. Jongmans and M. Ohrnberger (2004). Surface-wave inversion using direct search algorithm and its application to ambient vibration measurements, Near Surf. Geophys., 2, 211-221.

Wathelet, M. (2005). Array recordings of ambient vibrations: surface-waves inversion, $\mathrm{PhD}$ thesis, University of Liege, Belgium, 177 pp.

Wathelet, M., D. Jongmans and M. Ohrnberger (2005). Direct inversion of spatial autocorrelation curves with the neighborhood algorithm, B. Seismol. Soc. Am., 95, 1787-1800.

Weber, E., V. Convertito, G. Iannaccone, A. Zollo, A. Bobbio, L. Cantore, M. Corciulo, M. Di Crosta, L. Elia, C. Martino, A. Romeo and C. Satriano (2007). An advanced seismic network in southern Apennines (Italy) for seismicity investigations and experimentation with earthquake early warning, Seismol. Res. Lett., 78, 622-634.

Woods, J.W., and P.R. Lintz (1973). Plane waves at small arrays, Geophysics, 38, 1023-1041.
${ }^{\star}$ Corresponding author: Margherita Corciulo, Laboratoire de Géophysique Interne et Tectonophysique (LGIT), Université J. Fourier, Grenoble, France; e-mail: margherita.corciulo@obs.ujf-grenoble.fr.

(C) 2010 by the Istituto Nazionale di Geofisica e Vulcanologia. All rights reserved. 